\title{
A novel paradigm for auditory discrimination training with social reinforcement in songbirds
}

\author{
Kirill Tokarev, Ofer Tchernichovski
}

Dept. of Psychology, Hunter College and Research Foundation of the City University of New York, New York, NY

Supported by NSF grant \# 1261872

Zebra finches are a highly social, gregarious, species and eagerly engage in vocal communication. We have developed a training apparatus that allows training zebra finches to discriminate socially reinforced and aversive vocal stimuli. In our experiments, juvenile male zebra finches were trained to discriminate a song that was followed by a brief air puff (aversive) and a song that allowed them to stay in visual contact with another bird, 'audience' (social song). During training, the birds learned quickly to avoid air puffs by escaping the aversive song within 2 sec. They escaped significantly more aversive songs than socially reinforced ones, and this effect grew stronger with the number of training sessions. Therefore, we propose this training procedure as an effective method to teach zebra finches to discriminate between different auditory stimuli, which may also be used as a broader paradigm for addressing social reinforcement learning. The apparatus can be built from commercially available parts, and we are sharing the controlling software on our website.

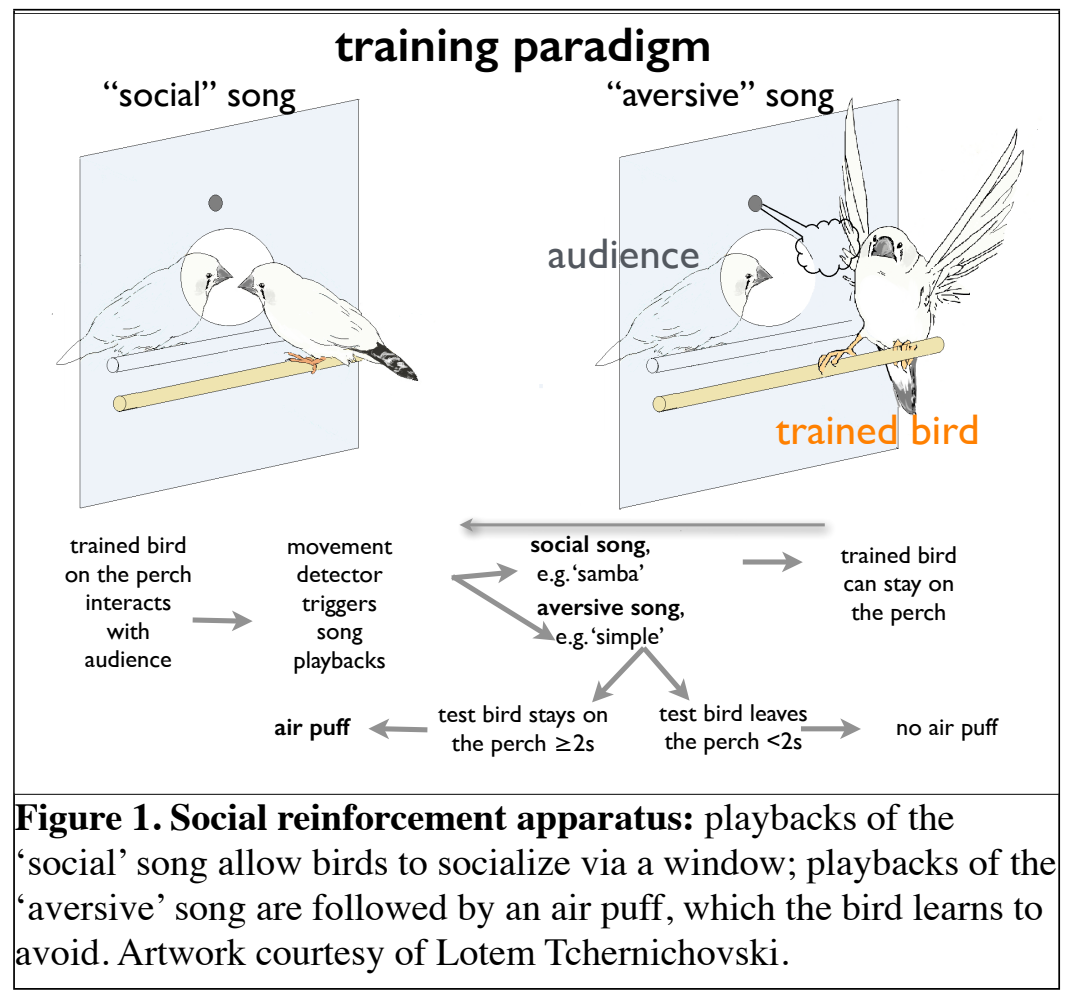

Zebra finch (Taeniopygia guttata) is a highly social, gregarious, species that lives in colonies with high mobility of members but monogamous pairs (Adkins-Regan, 2002; Goodson et al., 2012; Zann, 1994). Zebra finches use various vocal signals, for communication: multiple call types (Marler, 2004) and a male song, which varies slightly depending on whether it is directed to another individual or not (Jarvis et al., 1998; Sossinka and Böhner, 1980). There are multiple parallels between speech acquisition in humans and vocal imitation in songbirds (Bolhuis et al., 2010) at the 


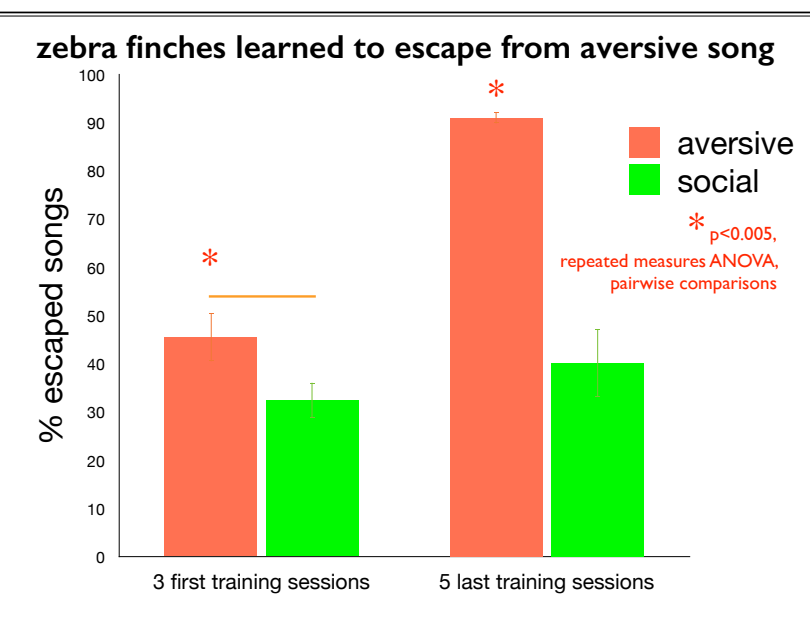

Figure 2. Zebra finches learned to escape from aversive song: Escape rates for the aversive song were significantly higher than for the social song even in the first three training sessions across 10 birds. In the last 5 sessions, this difference became even bigger, as the escape rate for the aversive song increased significantly compared to the first molecular (Fisher and Scharff, 2009), neuroanatomical (Jarvis, 2004) and behavioral levels (Doupe and Kuhl, 1999; Lipkind et al., 2013). Social aspect of vocal imitation in zebra finches attracts a lot of interest, but only few studies have addressed it directly. In accordance with the idea that individual recognition must be important in social groups of zebra finches, it is known that there is a preference towards mate's song in females (Clayton, 1988) and father's song in his offspring (Riebel et al., 2002), for example. Here, we propose a method that allows to study discrimination of songs and other auditory stimuli in zebra finches.

We exploited eagerness of zebra finches to engage in social communication (Goodson et al., 2012) as means for positive reinforcement in our training paradigm. We developed a social-reinforcement apparatus where birds can interact through a small window (Fig. 1).

Our system is similar to existing go-nogo song discrimination boxes (Cynx and Nottebohm, 1992; Scharff et al., 1998), but instead of food reward we offer the bird a social reward: the apparatus includes two chambers and a window, through which they can communicate. When our system detects the bird perching next to the window, it sparsely plays songs. One song has no consequences, allowing the birds to keep interacting (social song). The other song is followed by an air puff (aversive song), which the bird can prevent by escaping within 2 seconds.

We use a custom-built apparatus for these

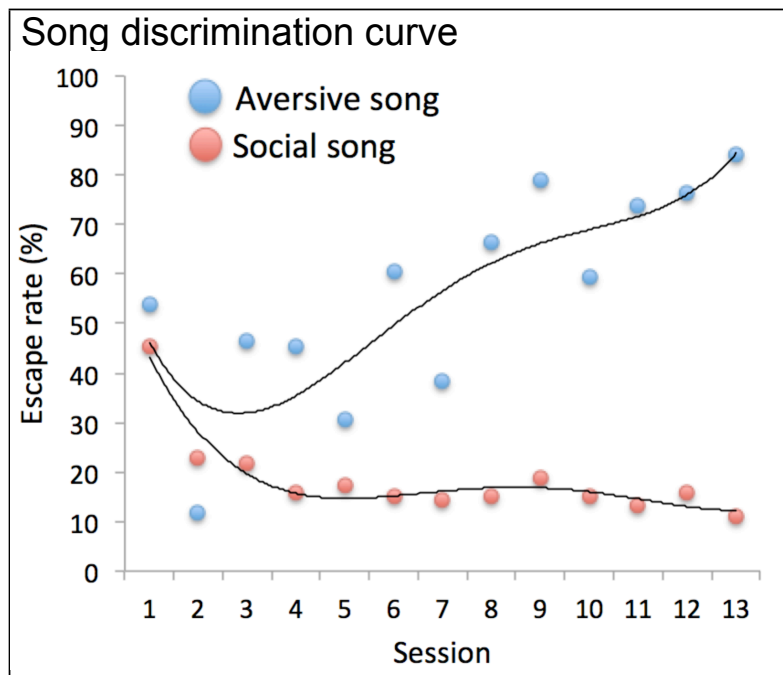

Figure 3. Discrimination curve for an individual

bird: Escape rates for the aversive song increased with the number of training sessions but decreased for the social song. experiments. Electric air valve solenoid (Assured Automotive Company) with a 12V $\mathrm{AC}$ power source delivers pressurized air through a hose. A sensor (SB12, Banner Engineering Corp.) uses invisible infra-red beam to detect presence of the bird at the perch next to the window between the chambers of the cage. These are connected to a PC via NI USB-6501 card (National Instruments Corp.), which in turn sends out the audio via a loudspeaker set at $80 \mathrm{db}$. OT wrote a software, "Bird Puffer", that controls this system and allows changing such parameters as length and delay of the air puff, odds for playbacks, selection of particular audio files etc. It automatically records each instance of the playback (social or aversive), and if the bird escaped it or not 
(within the time limit preset by the user). Bird Puffer is freely available on our website http:// ofer.sci.ccny.cuny.edu

During our pilot experiments, we used 10 pairs of male juvenile zebra finches kept in isolation except for the time of the training. One animal in each pair was trained in the compartment with air puffs, and the other served as the audience. The animals spent most of their time next to the window and in most cases learnt to discriminate songs within three one-hour sessions, as they escaped significantly more aversive songs than socially reinforced ones (Fig. 2 , left). The songs used for this experiment were recorded previously from two different birds, and their role (social vs aversive) was counterbalanced for different pairs. The difference between escape rates for the aversive and social songs only increased with the number of sessions, as the birds kept on escaping more and more aversive songs but not social ones (see example on Fig. 3). Escape rate from the aversive song was significantly higher in the last five sessions than in the first three, and in both cases it was higher than escape rates from the social song $(\mathrm{p}<0.005$, repeated measures ANOVA, pairwise comparisons; Fig. 2).

Thus, we provide an effective social reinforcement training paradigm for zebra finches, which we expect to be an important tool in understanding the social aspect of vocal imitation. 


\section{Bibliography}

Adkins-Regan, E., 2002. Development of sexual partner preference in the, zebra finch: A socially monogamous, pair-bonding animal. Arch Sex Behav 31, 27-33.

Bolhuis, J.J., Okanoya, K., Scharff, C., 2010. Twitter evolution: converging mechanisms in birdsong and human speech. Nat Rev Neurosci 11,747-759.

Clayton, N.S., 1988. Song Discrimination-Learning in Zebra Finches. Animal Behaviour 36, 1016-1024.

Cynx, J., Nottebohm, F., 1992. Role of gender, season, and familiarity in discrimination of conspecific song by zebra finches (Taeniopygia guttata). Proc Natl Acad Sci U S A 89, 1368-1371.

Doupe, A.J., Kuhl, P.K., 1999. Birdsong and human speech: common themes and mechanisms. Annu Rev Neurosci 22, 567-631.

Fisher, S.E., Scharff, C., 2009. FOXP2 as a molecular window into speech and language. Trends Genet 25, 166-177.

Goodson, J.L., Kelly, A.M., Kingsbury, M.A., 2012. Evolving nonapeptide mechanisms of gregariousness and social diversity in birds. Hormones and behavior 61, 239-250.

Jarvis, E.D., 2004. Learned birdsong and the neurobiology of human language. Ann N Y Acad Sci 1016, 749-777.

Jarvis, E.D., Scharff, C., Grossman, M.R., Ramos, J.A., Nottebohm, F., 1998. For whom the bird sings: context-dependent gene expression. Neuron 21, 775-788.

Lipkind, D., Marcus, G.F., Bemis, D.K., Sasahara, K., Jacoby, N., Takahasi, M., Suzuki, K., Feher, O., Ravbar, P., Okanoya, K., Tchernichovski, O., 2013. Stepwise acquisition of vocal combinatorial capacity in songbirds and human infants. Nature 498, 104-108.

Marler, P., 2004. Bird calls - Their potential for behavioral neurobiology. Ann Ny Acad Sci 1016, 31-44.

Riebel, K., Smallegange, I.M., Terpstra, N.J., Bolhuis, J.J., 2002. Sexual equality in zebra finch song preference: evidence for a dissociation between song recognition and production learning. P Roy Soc B-Biol Sci 269, 729-733.

Scharff, C., Nottebohm, F., Cynx, J., 1998. Conspecific and heterospecific song discrimination in male zebra finches with lesions in the anterior forebrain pathway. J Neurobiol 36, 81-90.

Sossinka, R., Böhner, J., 1980. Song types in the zebra finch (Poephila guttata castanotis). Z.Tierpsychol. 53, 123-132.

Zann, R.A., 1994. Reproduction in a Zebra Finch Colony in South-Eastern Australia - the Significance of Monogamy, Precocial Breeding and Multiple Broods in a Highly Mobile Species. Emu 94, 285-299. 